rale that it should be emptied. Draw off half or only two-thirds of a pint; you will thus relieve the organ partially, and in the course of a week or sooner you may mradually accomplish the entire emptying of the bladder, and all will probably go well. And it conduces greatly to success to permit no outdoor movement to such a patient, but confine him to his room, in a warm temperature, if the weather be cold, or even to his bed for a few days. The probationary period, while the use of the catheter has to be learned, and the onset of chronic cystitis with constitutional disturbance is to be feared, is more safely passed if absolute rest and quiet are accepted as necessary conditions by the patient. It is only within the last few years that I have pursued this course, and I. cannot speak too highly of the results. Nevertheless, very rarely, notwithstanding every precantion, you will find a case in which during this process the tongue grows slowly more red, dry, and contracted; the powers of life gradually fail, the senses become impaired, and the patient sinks. You will always find in such cases, if an autopsy is made, old-standing pyelitis, with dilatation and marked degeneration of the renal structure, and you will know that in no circumstances could the patient have long survived." (p. 57.)

The lesson to be learned-and it is an important one-is this. When the bladder of an elderly man fails to empty irself, let him learn to use a soft catheter without much delay: thus life with comfort may often be maintained to its natural term. Neglect the catheter until chronic disease of the organs is established, and a catastrophe may then be hastened by the use of the instrument. Scores of men whom I know in this town, between sixty and eighty years of age, still active, mature in mind, and more than ever serviceable to their fellows, owe their existence entirely to habitual catheterism. I am, Sir, yours obedient'y,

Wimpole-street, Oct. 20th, 1883.

HenRy Thompson.

\section{To the Editor of THE LANCET.}

SIR,-Sir Andrew Clark's observations on "Catheter Fever" in elderly males at the Clinical Society, and your comments thereupon, will be read with interest and cannot fail to draw forth discussion. Permit me to make a few remarks on the class of cases from which, in my experience, these instances are drawn, and which are distinguishable frem ordinary examples of urethral fever. I will for conreaience consider them under two headings.

1. Those cases where catheterism is commenced and continued with an absence of all signs of tranmatism. Here I cannot say that I ever saw fatal symptoms produced; at the most, a rigor has been provoked, just such a one as will sometimes follow urine passing along the urethra for the first time afte $\mathbf{r}$ ithotomy, but nothing further.

2. Those (a ses where catheterism is accompanied with traumatism, as indicated by some sign, such as urethral hamorrbage. Here I have seen fatal symptoms provoked, extending over several days, as described by Sir Andrew Clark. I have hitherto regarded these symptoms as due to septicemia. That they are connected with the infliction of a wound on the urinary passage is strengthened by some instances, where it has been obeerved that patients have for considerable periods submitted to catheterism with advan. tage, and symptoms of fatal pyrexia have only shown themselves when some mechanical difficulty in the introduction of the instrument has arisen and the infliction of a round, possibly only a slight one, on some part of the passage to the bladder has been the result. That a very slight lesion of the urethra is, in certain states of urinary disease, capable of causing septicæmia, there cannot, I think, be any doubt, though, possibly, the fact may not be sufficiently appreciated in association with the very common operation of passing the catheter.

In the last place, Sir Andrew Clark incidentally refers to those cases where these symptoms follow the tying-in of a catheter. The more I see of this method of treating the bladder troubles of old age, the more I am disposed to take exception to it. If it is desirable under these circumstances to establish a continuous flow of urine from the bladder, it is safer and more comfortable to the patient to provide a shorter and more direct route than by the urethra. This can be done from the perineum eitber by openiug the membranous urethra or perforating the prostate, as I have iecently adrocated. To tie a catheter in an old man with a large prostate and a chronically inflamed bladder is to expose him to the risk of generating pyelitis or of becoming septicæmic. The danger of wounding the urethra, as well as the necessity for retaining an instrument in the bladder, have undoubtedly been diminished by the marked improvements that bave receutly taken place in the construction of catheters, and their suhstitution by the profession for the old metallic one with the big curve, which, I am glad to say, is now rarely seen. - I am, Sir, yours truly, Liverpool, Oct. 22nd, $1883 . \quad$ REGINALD HARRISON.

\section{DR. JOSEPH ROGERS.}

\section{To the Editor of THE LANCET.}

SIR,-Since writing my letter to you last week, I am rejoiced to see that a movement has commenced for giving shape to the esteem in which Dr. Joseph Rogers is held by his professional bretbren and others who know his work. I hope a large sum will be raised, which cannot fail to be the case if all whom his labours have benefited give a little. And surely the time could not be more opportune than when in battle with his persecutors; he wants to the full the encouragsment of his friends. Only one suggestion I cannot agree with-viz, that the subscription list should be limited to Poor-law medical officers. Why? Truly, he has been a great benefactor to them, but not to them only. His public work has been much wider in aim and usefulness than simply to touch the pockets of a few Poor-law surgeons. Many years ago he was a leader in the movement that ended in stopping burials within towns. I believe I am right in saying that to his influence is largely due the establishment of mortuaries. It was he who succeeded in getting expensive medicines-which it was hopeless to expect the Poor-law officers to supply out of their slender salaries-supplied by boards of guardians ; an improvement directly benefiting the poor, and incirectly the ratepayers. The Metropolitan Poor Act of 1867 was largely brought about by his untiring zeal. From that what good has not flowed? The supply of not expensive medicines only, but all medicines by the guardians. The dispensary system, leading to a very large increase, probably not less than $£ 15,000$ a year, to the Metropolitan medical officers. Then that great boon, the Superannuation Act, is another monument of Dr. Rogers' energy. I do not wish to undervalue the labours of Dr. Brady and our other friends in and out of the House of Commons, but Dr. Brady himself would be the foremost to admit that he never would have been able to carry the point had it not been for Dr. Rogers' assistance. "Instant in season, out of season"; delivering addresses from town to town; giving advice and assistance to persecuted public servants all over the country; strengthening the hands of the weaker brethren in public and private-he has been for fourteen years a tower of strength to an important section of the community, whose power for good has been enhanced by his agency, which has again reacted on the whole naticn. In short, Dr. Rogers has been, and is, a great social reformer, and of his work all classes reap the fruit. But as a great American philosopher says, when the flat stone of a fine old abuse is overturned, there is a great squirming of the flat-patterned animals that have thriven in the darkness. Dr. Rogers has been turning over these stones for many years, and has been atiacked by the squirming animals, as is usually the case. It is for those who have been cast in a different mould, and can appreciate his valuable, arduous, and often thankless labours, to show their appreciation now. I am, Sir, yours respectfully,

Cardiff, Oct. 22nd, 1883. JAMES MILWARD, M.D.

\section{To the Editor of THE LANCET.}

SrR,-For a long series of years one man in the medical profession has boldly stood forward in maintaining the rights, and in endeavouring by every legitimate means to redress the wrongs, of the Poor-law medical officers of this country. As one unconnected entirely with Poor-law medical practice, I have, no doubt in common with a multitude of others, admired the courage and honesty with which this man, almost single-handed, has fought the battles of its medical officers. Had any one of them a real grievance or haldship to complain of, Dr. Rogers at once came to the 
front and became his champion. Now that he is, in his own person, the subject of an injustice, and a very serious one, for he is threatened with dismissal from his post as medical officer of the Westminster Union for doing that which in all honesty he felt compelled to do, it behoves the whole profession to give him all the moral support in its power. It cannot surely be possible that the Local Government Board will ever sanction such manifest injustice. But this is not purely a question between the Westminster guardians and Dr. Rogers; but one which aims a blow at professional honour and rectitude, and if settled in the way in which the guardians would have it, it may be the means of preventing some members of our body, however rightminded they may be, from giving evidence of wrong-doing, or performing other necessary duties not falling strictly within the scope of their ordinary work; because, forsooth, they may, if they do, find themselves stranded and deprived of their appointments.

Let the profession, then, as a body, and not merely the Poor-law medical officers, rally round Dr. Rogers, and whilst recognising the benefits derived from his unselfish public labours in their behalf, labours which may have brought upon him much obloquy, and perhaps have had something to do with his present trial, present him with such a testimonial as shall effectually demonstrate to the Local Government Board its approval of his conduct, and its disapprobation of the ungenerous treatment to which he has been subjected by the Westminster guardians.

"He's true to God who's true to man wherever wrong is done: To the humblest or the weakest 'neath the all beholding sun. Whose love of right is for themselves and not for all the race." I am, Sir, your obedient servant,

Wirksworth, Oct. 24th, 1883 WILLAAM WEBB, M.D., F.R.C.S,

\section{To the Editor of THE LANCET.}

SIR, - Will you permit me to draw the attention of your readers to a movement which has bzen set on foot with the view of presenting to Dr. Joseph Rogers, the President of the Poor-law Medical Officers' Association, a testimonial as a mark of the esteem in which he is held by Poor-law medical officers, and as a recognition of his unwearied advocacy of their claims, his fearless exposure of injustice done to them, and the able assistance and advice which he has freely given to such of them as have been unfortunate enough to be at variance with their Boards.

The unjust treatment Dr. Rogers has received at the hands of the Westminster guardians will, I hope, shortly be brought before the Local Government Board. But I venture to suggest that no better time than the present could be chosen for his fellow officers to express their sympathy with him, and that such an expression from a large number would show that they have appreciated his labours on their behalf; that in a good cause they are capable of acting in concert, and that they respect themselves and their office in manifesting respect for one who has fearlessly done his duty, although for doing it he has received the usual punishment accorded by guardians to parochial medical officers.

The following gentlemen have kindly promised to receive subscriptions-viz. : Ernest Hart, Esq., Editor of the British Medical Joumal; C. Frost, Esq. (Treasurer of the Poor-law Medical Officers' Association), 47, Ladbrokesquare, Notting-hill, London; J. Wickham Barnes, Esq. (Secretary of the Poor-law Medical Officers' Association), 3, Bolt-court, Fleet-street, London.

I am, Sir, yours faithfully,

Shrewsbury, October 23rd, $1883 . \quad$ FRANCIS WHITWELL.

* * We also shall be happy to receive subscriptions in aid of the object mentioned in the above letters.-ED. L.

\section{CASE OF CHLORAL POISONING.} To the Editor of THE LANCET.

SIR,-Thinking that the following case may be of interest from a toxicological and therapeutical point of view, I am induced to send you the account of it.

The patient, a gentleman twenty-six years of age, was suffering extreme pain from syphilitic rupia, for which I prescribed the following mixture in order to relieve his pain and induce sleep: Chloral hydrate, six drachms; bromide of potassium, half an ounce; orange water, four ounces; two drachms of the solution to be taken at bedtime. The patient (wilfully) swallowed the whole contents except one ounce, The draught must have been taken about midnight, and the patient was not seen till next morning at eight o'cluck, when his mother saw hin, and she, thinking he was sleeping naturally, did not disturb him. He was again seen at ten o'clock, when an effort was made to wake him, which, how. ever, was unsuccessful. I was then sent for, and on my arrival at half-past twelve he was in the following condition: He was lying on his back; eyes and mouth wide open; conjunctivæ injected and pupils contracted; congestion of his capillary system generally; breathing heavily ; complete muscular relaxation and reflex action abolished; pulse slow and full; temperature $102^{\circ}$. He was with some difficulty aroused, but by continuous efforts was kept awake and so far roused as to be persuaded to swallow some strong black coffee. By both vocal and physical means he was at length aroused to a sense of his position; but as soon as these efforts were relaxed he relapsed into the drowsy condition. Strychnine was then administered, and instructions given to keep him awake. In three hours' time he was com. pletely conscious, and felt quite well except for a feeling of lassitude. The strychniue was repeated, and during the afternoon he was quite prepared for dinner. His temperature fell $2^{\circ}$, and his pulse regained its natural strength and volume. His return of consciousness, he himself states, was just subsequent to his having the coffee, and his prior loss of consciousness was immediately after swallow: ing the chloral. To my positive knowledge no narcotic had been taken for at least six months previous to this occurrence, but at that time he could take four grains of solid opium. Chloral he has had on two occasions, in sixty grain doses. Bromide he never had before. On this occasion he swallowed 270 grains of chloral, or nearly five drachms, combined with three drachms of bromicie. Such is the history of the case; its full value is lost of course, owing to the length of time elapsing between the taking of the poison and the notifying of the symptoms. Ten hours had elapsed before my seeing him, but I think had he been allowed to continue his slumbers undisturbed the result would have been the samenamely, complete recovery. The poisonous effects must have been much more decided during the hours immediately succeeding his taking the draught.

Dr. Levenstein reports a case where the dose taken was six drachms, and recovery ensued. But in his case twenty. four hours elapsed before consciousness was restored, and that only after continuous treatment from the first hour of the poison being taken.

I am, Sir, yours obediently,

Glasgow, Oct. 1883. ARTHUR MeChaN, M.B. C.M. Glasg.

\section{"THE SISTERHOOD OF ST. JOHN'S: HOUSE." To the Editor of THE LANCET.}

SIR,-I have observed with great regret that in last week's LANCET a very grave charge is brought against those of the late sisters of St. John's House who nursed the wards in Charing-cross Hospital. It is stated that they, "without any real grievance, but to show their common sympathy with the sister matron at King's College Hospital, resigned their posts and left the patients to be cared for as chance or good fortune might determine." And a little further on in the same paragraph : "We can hardly believe that the other nembers of the Council [of Charing-eross Hospital] and the medical authorities will quietly give way to Mr. Few's wishes, and allow the nursing to be handed over to an irresponsible sisterhood" (referring, I presume, to the sisters of St. John the Divine, who formerly constituted the sisterhood of St. John's House), "whose members may again leave on the slightest pretext and without warning, "thes implying that they have already done so.

Now, Sir, may I be permitted to state that this charge is absolutely without foundation, and therefore manifestly unjust, and it can only have been made in the hope of injuring the sisters. The sisters certainly did leave Charing. cross Hospital ; but why? for the sole reason that the hos. pital was closed for repairs, and they were quite ready to resume the nursing on the hospital being re-opened. In fact, the late sister in charge at the hospital wrote a letter, which was laid before the Board at a meeting on July $18 \mathrm{th}$, and in which she offered to again nadertake the nursing with the same 